\title{
A preovulatory temperature gradient between the isthmus and ampulla of pig oviducts during the phase of sperm storage
}

\author{
R. H. F. Hunter and R. Nichol \\ School of Agriculture, University of Edinburgh, West Mains Road, Edinburgh EH9 3JG, U.K.
}

\begin{abstract}
Summary. Fine thermistor probes positioned in each end of the same oviduct and connected to the same scale were used to measure temperature gradients in the lumen before and after spontaneous ovulation in normally-cyclic gilts. Readings were taken after full surgical closure of a mid-ventral incision and a subsequent period of stabilization, but whilst animals remained under general anaesthesia.

A small but consistent difference in temperature was recorded between the proximal ampulla and distal isthmus of the same oviduct in each of 20 preovulatory gilts. In 10 of these animals that had not mated, the isthmus was a mean of $0.43^{\circ} \mathrm{C}$ cooler than the ampulla (range $0 \cdot 2-0.7^{\circ} \mathrm{C}$ ) whereas in 10 mated animals the isthmus was $0.69^{\circ} \mathrm{C}$ cooler (range $0 \cdot 2-1 \cdot 6^{\circ} \mathrm{C}$ ); 3 animals in the latter group had within-oviduct differences of $\geqslant 1^{\circ} \mathrm{C}$. By contrast, in 12 animals that had recently ovulated, the isthmus was a mean of only $0 \cdot 1{ }^{\circ} \mathrm{C}$ cooler than the ampulla; there was no measurable temperature gradient in 3 of the animals, whilst the isthmus was $0.1{ }^{\circ} \mathrm{C}$ warmer in 2 animals. The preovulatory temperature differences are thought primarily to reflect the extent and activity of the vascular and lymphatic beds in the oviduct tissues and, together with specific chemical microenvironments, may facilitate the relatively prolonged period of sperm storage in the distal portion of the isthmus.
\end{abstract}

\section{Introduction}

Recent studies of cows, sheep and pigs have shown that, after mating at the onset of oestrus, a population of spermatozoa competent to fertilize the eggs passes to the caudal portion of the oviduct where it is then arrested for much of the preovulatory interval (Hunter \& Nichol, 1983, 1986; Hunter, 1984; Hunter \& Wilmut, 1984; Wilmut \& Hunter, 1984). This strategy of sperm storage in the oviduct isthmus maintains viable spermatozoa beyond the reaches of polymorphonuclear leucocytes which infiltrate the uterine lumen as a response to mating or artificial insemination (Lovell \& Getty, 1968; Polge, 1978). Arrest of spermatozoa in a pre-capacitated state with intact plasma and acrosomal membranes would clearly be beneficial for the phase of storage and preservation of subsequent fertilizing ability (Hunter \& Nichol, 1983), as would location of this functional reservoir close to the site of fertilization. In the latter regard, the caudal region of the oviduct isthmus that appears to have evolved as a temporary storage site for viable spermatozoa is also a region of the duct exposed to high concentrations of ovarian follicular hormones due to a local counter-current transfer mechanism (Hunter, Cook \& Poyser, 1983); its tissues can therefore be subjected to a form of preovulatory endocrine programming so that spermatozoa are activated and displaced to the site of fertilization at the ampullary-isthmic junction shortly before the eggs are released.

The range of physiological factors underlying the phase of sperm storage is uncertain, although there is evidence for different microenvironments within the oviduct. Burkman, Overstreet \& Katz 
(1984) provided circumstantial evidence for differences in the composition of isthmic versus ampullary fluid in rabbits before ovulation, with the specific suggestion that $\mathrm{K}^{+}$might inhibit and pyruvate stimulate sperm motility in the isthmus. Earlier studies on the environment in which mouse embryos begin to develop had also indicated regional variation in the composition of oviduct fluid, and had highlighted differences in the concentrations of potassium, sulphur and phosphorus (Borland, Hazra, Biggers \& Lechene, 1977). However, a factor as simple as a reduced temperature before ovulation might also contribute to the storage phenomenon and, indirectly, to changes of gas tension and chemical composition in the duct lumen. A temperature difference within the oviduct has already been reported in relation to ovarian steroid status in rabbits (David, Vilensky \& Nathan, 1972), but the findings were not considered in the context of sperm storage and the subsequent events of fertilization.

In the light of our own previous studies on sperm transport and storage, and because of the significantly longer preovulatory interval in domestic pigs than in rabbits or mice, we have now measured temperatures in the oviduct isthmus and ampulla before and after ovulation.

\section{Materials and Methods}

Experimental animals. Forty-one sexually mature Large White $\times$ Landrace gilts from the School of Agriculture herd were used; they were aged 6.5-9.5 months and weighed 91-138 kg. They were penned as groups of 5-8, maintained under natural lighting, fed a proprietary diet, and checked for sexual behaviour with a mature teaser boar at 09:00 and 16:00 h. During late pro-oestrus, animals were checked individually every $3-4 \mathrm{~h}$ for the onset of standing oestrus and therefore the approximate time of the preovulatory surge of gonadotrophic hormones (see Liptrap \& Raeside, 1966; Niswender, Reichert \& Zimmerman, 1970; Foxcroft \& Van de Wiel, 1982). Ovulation occurs $40-42 \mathrm{~h}$ after this surge, or after a pro-oestrous injection of 250-500 i.u. hCG (Dziuk, Polge \& Rowson, 1964; Hunter, 1967; Dziuk, 1973). Nineteen of the animals were mated once with a fertile boar during the first $6 \mathrm{~h}$ of oestrus.

Surgical intervention. Oestrous animals remained in their pens and were only brought to the preoperative room immediately before the experiment. The surgical building was adjacent to the holding pens, and animals walked across the intervening 20 metres. Anaesthesia was induced with an intravenous injection of pentobarbitone sodium (Nembutal; Ceva Ltd, Rhodes Way, Watford, Herts, U.K.) and, after endotracheal intubation, maintained by semi-closed circuit administration of halothane (Fluothane; ICI Pharmaceuticals, Macclesfield, Cheshire, U.K.), nitrous oxide and oxygen. Animals were placed horizontally on a sponge rubber-insulated operating table. The temperature in the operating theatre during the study varied from 20 to $24^{\circ} \mathrm{C}$.

Observing strict aseptic precautions, the reproductive tract was exposed through a mid-ventral incision. The ovaries were examined briefly to confirm whether ovulation had occurred, one oviduct was selected at random for temperature recordings, and the contralateral oviduct and uterine horn were restored to the abdominal cavity to reduce heat loss.

Temperature measurements. Temperatures within the lumen of the oviduct were measured by using fine thermistor probes. These were made from individual thermistor beads $(0.5 \mathrm{~mm}$ diameter) glued with Araldite (Ciba-Geigy, Horsham, Sussex, U.K.) into a polythene cannula and connected with a $20 \mu \mathrm{m}$ diamel-coated silver wire to the main leads. The probes were prepared in the Department of Physiology, University of Edinburgh Medical School, and kindly made available by Mr T. Mackenzie. The two polythene-coated thermistor probes, labelled A and B, were connected to the same thermistor amplifier with a single scale extending from 36 to $39^{\circ} \mathrm{C}$ and accurate to $0.05^{\circ} \mathrm{C}$ (Fig. 1). The coincidence of the two thermistor readings on this scale was verified before and after each experiment by placing the two probes together in the water-filled barrel of an inverted $1 \mathrm{ml}$ Gillette Scimitar plastic syringe, itself maintained in a glass beaker water bath $(500 \mathrm{ml})$ within a 


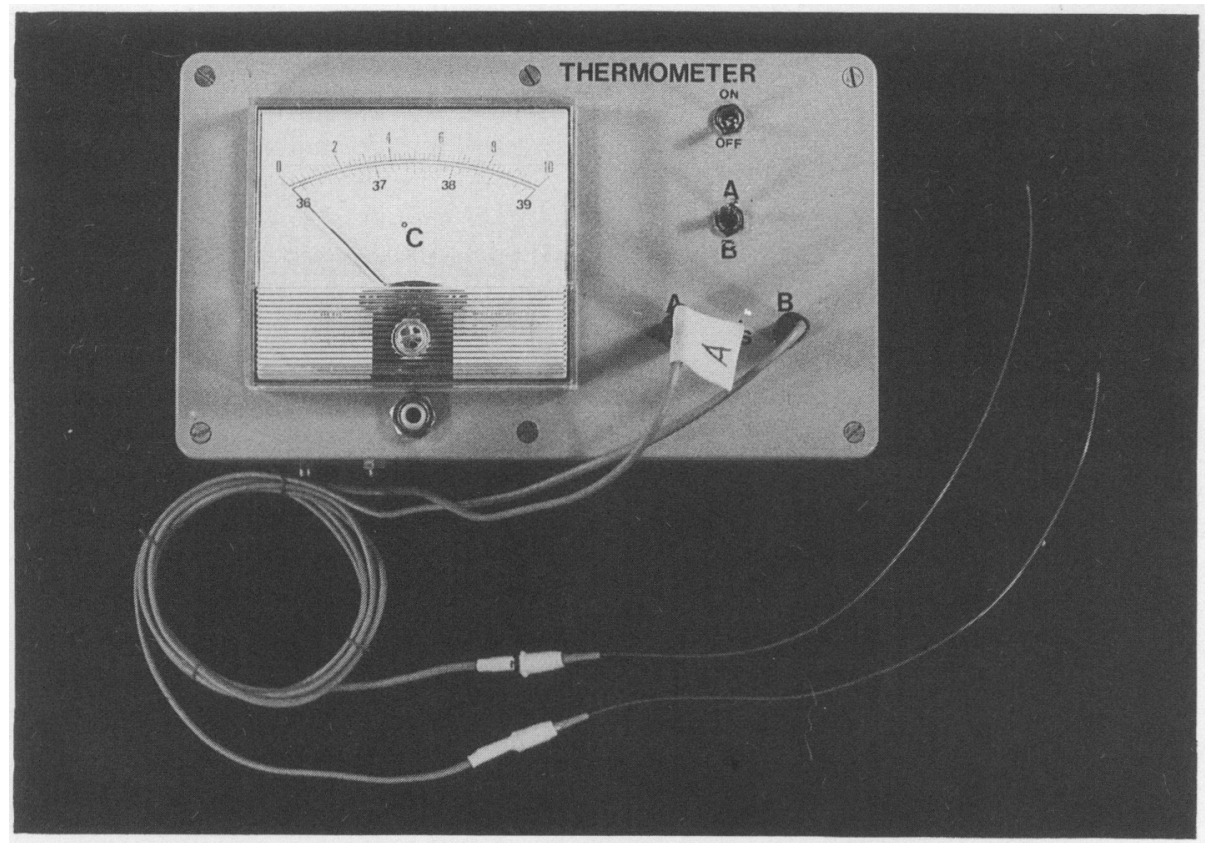

Fig. 1. The apparatus used for measuring regional temperature differences in the lumen of the oviduct. Individual thermistor probes labelled A and B are connected to the same amplifier with a scale extending from 36 to $39^{\circ} \mathrm{C}$. Coincidence of readings from the two probes on this temperature scale was checked before and after each experiment (a means exists for fine adjustments).

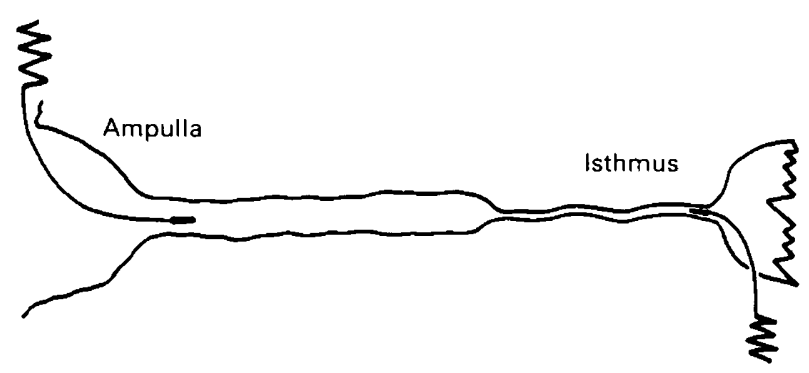

Fig. 2. Semi-diagrammatic representation of a pig oviduct to show the siting of individual thermistor probes used for measuring temperatures in the oviduct lumen. The probe in the ampulla was inserted via the fimbriated extremity of the oviduct whereas access to the caudal region of the isthmus was gained by passing the probe through the uterine wall and utero-tubal junction. Individual oviducts in the experimental animals measured approximately $27 \mathrm{~cm}$ in length.

large laboratory incubator at $38^{\circ} \mathrm{C}$. This arrangement avoided detectable convection currents in the water surrounding the thermistors. Individual probes were selected at random for insertion into each end of the same oviduct. A record was kept of the location of each probe in each animal.

The thermistor probe to be sited in the ampulla was inserted via the fimbriated extremity of the oviduct until its tip was $2-3 \mathrm{~cm}$ below the infundibulum (Fig. 2). It was anchored with two fine silk ligatures (Mersilk, No. 2 gauge; Ethicon Ltd, Edinburgh, U.K.), placed at least $2 \mathrm{~cm}$ behind the tip of the probe. Care was taken to avoid damaging or ligating conspicuous blood vessels. Access to 
the caudal region of the isthmus was gained by puncturing the wall of the uterus some $2 \mathrm{~cm}$ distal to the utero-tubal junction; the actual puncture was made with a blunt-tipped (polished) dissecting needle. The probe was inserted at this site and carefully negotiated through the folds of the utero-tubal junction. It was anchored by means of a single silk ligature placed around the puncture of the uterine wall such that the tip of the probe was $1 \cdot 5-2 \mathrm{~cm}$ into the isthmus (Fig. 2).

These procedures were achieved as rapidly as possible and with an absolute minimum of handling of oviduct tissues, after which the reproductive tract was replaced and the incision closed with continuous sutures in the body wall and skin. The incision was covered with a double surgical drape, and the tissues left to stabilize for 3-5 min. Oviduct temperatures were then recorded every 5 min for 35-40 min, as were respiration and heart rates. The concentration of halothane in the gas phase was usually $2 \%$, with spontaneous respiration occurring throughout.

Subsequent procedures. The reproductive tract was exposed once more, the probes were checked as being securely and correctly in place, and were then removed. The incision was closed in three layers. All animals were slaughtered 1 or 2 days after the operation and the tract was recovered. The side into which the probes had been inserted was noted, and a count was made of the number of young corpora lutea (i.e. recent ovulations) on each ovary.

Statistical analysis. The significance of mean differences in temperature was assessed after analysis of variance by comparison of least significant differences against an appropriate $t$ value.

\section{Results}

The main results are summarized in Tables 1 and 2, but observations from 9 of the 41 animals have been excluded for the following reasons: the temperature measurements were off the lower end of the scale in 2 animals; there was undue difficulty in inserting a probe through the utero-tubal junction in 3 animals, and thus excessive exposure and handling of the tissues; and the probe had slipped from the isthmus back into the uterus in a further 3 animals. In a 9 th animal, the probe placed in the isthmus was found to be some $3 \cdot 5-4 \mathrm{~cm}$ beyond the utero-tubal junction at recovery.

The most clear-cut observation in the 20 preovulatory animals was that of a small but consistent decrease in temperature between the proximal ampulla and caudal isthmus of the same oviduct. In 10 preovulatory animals that had not been mated, the mean difference was $0.43^{\circ} \mathrm{C}$, with a range from 0.2 to $0.7^{\circ} \mathrm{C}$ (Table 1a). In 10 mated preovulatory animals, by contrast, the mean difference was $0.69^{\circ} \mathrm{C}(P<0.05)$, with a range of $0.2-1.6^{\circ} \mathrm{C}$ (Table $\left.1 \mathrm{~b}\right) ; 3$ of these animals had temperature differences of $\geqslant 1{ }^{\circ} \mathrm{C}$. Strictly speaking, 2 of the animals in Table $1(\mathrm{~b})$ were periovulatory, being just in the process of ovulating their respective total populations of 13 and 14 Graafian follicles. There was no simple relationship between the stage of oestrus and the temperature gradient in the oviduct, nor could a correlation be demonstrated between the number of mature follicles on the adjacent ovary and the temperature gradient.

Smaller numbers of post-ovulatory animals were examined (Table 2), since prolonged sperm storage in the caudal region of the isthmus was not anticipated after the first stages of fertilization would have occurred. The temperature difference between the isthmus and ampulla was small (mean of $0.1{ }^{\circ} \mathrm{C}$ ) and significantly less $(P<0.05)$ when compared with the mean of both preovulatory groups. Likewise, the range in temperature difference about the mean $\left(0 \cdot 0-0 \cdot 3^{\circ} \mathrm{C}\right)$ in these 12 animals contrasted with the preovulatory situation. There was no measurable temperature gradient in 3 of the animals and, in a further 2 , the isthmus was $0 \cdot 1{ }^{\circ} \mathrm{C}$ warmer than the ampulla (Table 2). No distinction could be drawn between measurements in mated and unmated post-ovulatory animals.

There was a small but progressive reduction in oviduct temperature during the 40 -min period of observation, the mean drop being $0.5^{\circ} \mathrm{C}$ with a range of $0 \cdot 2-0.9^{\circ} \mathrm{C}$. This fall in temperature occurred at both ends of the oviduct, and therefore did not influence the recorded differences 
Table 1. Details of the temperature gradient within the same oviduct in preovulatory animals in relation to the stage of oestrus and number of large ( $>8 \mathrm{~mm}$ diam.) Graafian follicles in the neighbouring ovary

\begin{tabular}{cccccc}
\hline $\begin{array}{c}\text { Animal } \\
\text { no. }\end{array}$ & $\begin{array}{c}\text { Stage of } \\
\text { oestrus }\end{array}$ & $\begin{array}{c}\text { No. of mature } \\
\text { follicles in the } \\
\text { adjacent ovary }\end{array}$ & $\begin{array}{c}\text { Temp. }\left({ }^{\circ} \mathrm{C}\right) \\
\text { probe in } \\
\text { isthmus }\end{array}$ & $\begin{array}{c}\text { Temp. }\left({ }^{\circ} \mathrm{C}\right) \\
\text { probe in } \\
\text { ampulla* }\end{array}$ & $\begin{array}{c}\text { Temp. difference } \\
\text { between isthmus } \\
\text { and ampulla }\left({ }^{\circ} \mathrm{C}\right)\end{array}$ \\
\hline
\end{tabular}

(a) Unmated pigs

$\begin{array}{llrlll}\text { H23 } & \text { 1st day, p.m. } & 11 & 37.9 \pm 0.08 & 38.5 \pm 0.05 & 0.6 \\ \text { O55 } & \text { 1st day, p.m. } & 7 & 38.5 \pm 0.15 & 38.7 \pm 0.03 & 0.2 \\ \text { H24 } & \text { 1st day, a.m. } & 4 & 38.6 \pm 0.08 & 38.9 \pm 0.10 & 0.3 \\ \text { H11 } & \text { 1st day, a.m. } & 8 & 38.1 \pm 0.07 & 38.4 \pm 0.09 & 0.3 \\ \text { O58 } & \text { 1st day, a.m. } & 5 & 37.9 \pm 0.21 & 38.5 \pm 0.27 & 0.6 \\ \text { H32 } & \text { 2nd day, a.m. } & 6 & 37.0 \pm 0.12 & 37.5 \pm 0.07 & 0.5 \\ \text { Y11 } & \text { 2nd day, a.m. } & 10 & 37.0 \pm 0.11 & 37 \cdot 7 \pm 0.12 & 0.7 \\ \text { Y12 } & \text { 2nd day, p.m. } & 7 & 38.2 \pm 0.12 & 38.5 \pm 0.10 & 0.3 \\ \text { Y16 } & \text { 2nd day, a.m. } & 6 & 37.1 \pm 0.04 & 37.6 \pm 0.03 & 0.5 \\ \text { Y27 } & \text { 1st day, p.m. } & 6 & 37.5 \pm 0.08 & 37.8 \pm 0.08 & 0.3\end{array}$

\section{(b) Mated pigs}

$\begin{array}{ll}\text { Y29 } & \text { 1st day, p.m. } \\ \text { Y30 } & \text { 1st day, p.m. } \\ \text { A13 } & \text { 1st day, p.m. } \\ \text { Y35 } & \text { 1st day, a.m. } \\ \text { Y41 } & \text { 1st day, p.m. } \\ \text { A17 } & \text { 2nd day, a.m. } \\ \text { Y43 } & \text { 2nd day, a.m. } \\ \text { Y44 } & \text { 2nd day, a.m. } \\ \text { Y48 } \dagger & \text { 2nd day, p.m. } \\ \text { Y49 } & \text { 2nd day, p.m. }\end{array}$

$\begin{array}{lll}37.1 \pm 0.11 & 38.6 \pm 0.12 & 1.5 \\ 36.8 \pm 0.02 & 38.4 \pm 0.10 & 1.6 \\ 37.6 \pm 0.08 & 37.9 \pm 0.10 & 0.3 \\ 36.9 \pm 0.10 & 37.4 \pm 0.09 & 0.5 \\ 37.1 \pm 0.06 & 37.3 \pm 0 \cdot 10 & 0.2 \\ 37.3 \pm 0.10 & 38.1 \pm 0.07 & 0.8 \\ 37.2 \pm 0.10 & 37.4 \pm 0.08 & 0.2 \\ 37.0 \pm 0.07 & 37.3 \pm 0.05 & 0.3 \\ 37.6 \pm 0.12 & 38.1 \pm 0.11 & 0.5 \\ 37.1 \pm 0.05 & 38.1 \pm 0.12 & 1.0\end{array}$

*Mean \pm s.e.m. of 6-8 readings taken every 5 min after a period of equilibration with the reproductive tract restored to the abdomen and the incision closed.

†These two animals were just starting to ovulate at laparotomy.

Table 2. Details of the temperature gradient within the same oviduct in each of 8 unmated and 4 mated post-ovulatory animals in relation to the number of recent ovulations in the adjacent ovary

\begin{tabular}{|c|c|c|c|c|}
\hline $\begin{array}{c}\text { Animal } \\
\text { no. }\end{array}$ & $\begin{array}{l}\text { No. of recent } \\
\text { ovulations in } \\
\text { adjacent ovary }\end{array}$ & $\begin{array}{l}\text { Temp. }\left({ }^{\circ} \mathrm{C}\right) \\
\text { probe in } \\
\text { isthmus }\end{array}$ & $\begin{array}{l}\text { Temp. }\left({ }^{\circ} \mathrm{C}\right) \\
\text { probe in } \\
\text { ampulla }\end{array}$ & $\begin{array}{l}\text { Temp. difference } \\
\text { between isthmus } \\
\text { and ampulla }\left({ }^{\circ} \mathrm{C}\right)\end{array}$ \\
\hline \multicolumn{5}{|l|}{ Mated } \\
\hline Y15 & 7 & $38.6 \pm 0.12$ & $38.5 \pm 0.08$ & $0 \cdot 1 \dagger$ \\
\hline Y02 & 6 & $38.5 \pm 0.0$ & $38.5 \pm 0.0$ & 0.0 \\
\hline Y19 & 5 & $37 \cdot 3 \pm 0 \cdot 10$ & $37.5 \pm 0.11$ & $0 \cdot 2$ \\
\hline Y 23 & 7 & $37 \cdot 3 \pm 0 \cdot 10$ & $37.6 \pm 0.09$ & 0.3 \\
\hline Y26 & 8 & $37.9 \pm 0.07$ & $37.8 \pm 0.12$ & $0 \cdot 1 \dagger$ \\
\hline Y14 & 5 & $38.1 \pm 0.12$ & $38 \cdot 2 \pm 0 \cdot 09$ & $0 \cdot 1$ \\
\hline Y31 & 9 & $36.3 \pm 0.0$ & $36.3 \pm 0.0$ & 0.0 \\
\hline $\mathrm{Z} 02$ & 6 & $38.2 \pm 0.11$ & $38 \cdot 3 \pm 0 \cdot 10$ & $0 \cdot 1$ \\
\hline \multicolumn{5}{|c|}{ Not mated } \\
\hline Y28 & 4 & $36.9 \pm 0.05$ & $37.0 \pm 0.05$ & $0 \cdot 1$ \\
\hline Y36 & 9 & $37.0 \pm 0.06$ & $37 \cdot 1 \pm 0.09$ & 0.1 \\
\hline Y13 & 4 & $37.3 \pm 0.08$ & $37.5 \pm 0.03$ & 0.2 \\
\hline Z03 & 5 & $38.3 \pm 0.0$ & $38.3 \pm 0.0$ & 0.0 \\
\hline
\end{tabular}

*Mean \pm s.e.m. of $6-8$ readings taken every 5 min after a period of equilibration with the reproductive tract restored to the abdomen and the incision closed.

$\dagger$ The temperature in the isthmus was $0 \cdot 1^{\circ} \mathrm{C}$ warmer than in the ampulla. 
between caudal isthmus and proximal ampulla. Respiration rates during this time varied from 5 to $9 / \mathrm{min}$ between animals, and heart rates from 72 to $99 / \mathrm{min}$.

\section{Discussion}

At first sight, the principal finding in this study of a preovulatory difference in luminal temperature between isthmus and ampulla of the same oviduct may cause surprise. Adjoining portions of tissue deep within the abdomen might not have been expected to show measurable differences of temperature, although the thick-walled isthmus of the pig oviduct has an extensive lymphatic network and differs in form from the thin-walled and highly vascular ampulla (see Andersen, 1928; Hunter, 1977), and the oviducts of these animals may measure $\sim 27 \mathrm{~cm}$ in length (Hunter, 1984). Even so, and in line with previous observations in the rabbit (David et al., 1972), the current findings using carefully calibrated thermistor probes indicate consistent temperature differences before ovulation, with the caudal portion of the isthmus always cooler than the proximal ampulla. Variation between animals in the extent of the differences might have been due to the stage of oestrus at surgery, and hence the size and synthetic activity of preovulatory follicles in the neighbouring ovary, and/or the precise siting of the two thermistor probes within the duct, especially the one in the isthmus. Future experiments could aim to reduce these sources of variation, possibly by using semi-permanent indwelling probes and monitoring temperature changes throughout the period of oestrus in conscious animals.

Whilst the mean preovulatory temperature difference between the lumen of the isthmus and ampulla in the 10 unmated animals was only $0.43^{\circ} \mathrm{C}$ (range $0.2-0.7^{\circ} \mathrm{C}$ ), there are grounds for believing that a steeper gradient might exist in the physiological situation. First, introduction of a probe through the complex folds of the utero-tubal junction (see Figs 1-4 in Fléchon \& Hunter, 1981) and into the caudal isthmus may have stimulated dilatation of the vascular and lymphatic beds in this portion of the duct, and thereby have reduced the apparent temperature difference between the isthmus and ampulla. Second, the site of fertilization is the ampullary-isthmic junction, and a probe placed there rather than at the fimbriated end of the ampulla might have recorded higher temperatures, as has been noted for rabbits (David et al., 1972). However, passage of the probe along $18-19 \mathrm{~cm}$ of convoluted ampulla would itself have caused artefacts. Third, mating and the consequent bathing of the uterine side of the utero-tubal junction in seminal plasma may be a necessary preliminary to the physiological modification in the caudal isthmus; some evidence for this comes from our measurements in the 10 preovulatory and mated animals in which there was a significantly greater temperature gradient than in unmated animals. A precise role for individual components of the seminal plasma in modifying the tissues of the caudal isthmus still requires clarification (see Einarsson \& Viring, 1973), but use of radiolabelled boar inseminates suggests that very small amounts of seminal plasma can enter the terminal portion of the oviducts soon after mating (Einarsson, Jones, Larsson \& Viring, 1980).

Assuming that differences in luminal temperature primarily reflect modifications in the extent and activity of the vascular and lymphatic beds of the oviduct tissues, but perhaps also the influence of local waves of contraction in the ampulla, then most probably there would be accompanying changes in gas tension $\left(\mathrm{PO}_{2}, \mathrm{PCO}_{2}\right)$, secretion and/or transudation in the duct associated with the preovulatory phase of sperm arrest and storage; these are currently being examined. Some evidence already exists for microenvironments in the oviduct that act to inhibit or stimulate sperm motility in rabbits (Burkman et al., 1984), and we have strongly emphasized parallels between the site of transient sperm storage in the Müllerian ducts and that of more prolonged storage in the epididymal region of the Wolffian ducts (Hunter \& Nichol, 1983; Hunter \& Wilmut, 1984), where specific proteins may act to inhibit sperm motility (Usselman \& Cone, 1983; Carr \& Acott, 1984). These factors may bear on the proposed suppression of capacitation before ovulation and the completion of this final and essential functional change in the 
spermatozoon close to the time of ovulation (see Hunter \& Nichol, 1983; Hunter, 1984). Moreover, after their escape from the bulk of the seminal plasma in the uterus, boar spermatozoa resuspended in fluids of the oviduct isthmus may be especially sensitive to a lowered preovulatory and then elevated peri-ovulatory temperature, as well as to other components of the microenvironment.

As noted in the 'Introduction', a counter-current mechanism has been demonstrated in pigs between the ovarian vein and the utero-tubal branch of the ovarian artery (Hunter et al., 1983), and likewise between the vein and artery within the vascular pedicle (Krzymowski, Kotwica \& Stefanczyk, 1981). This local route for the transfer of elevated concentrations of ovarian follicular hormones may enable incisive programming of the ducts so that spermatozoa are activated and released to the site of fertilization just before ovulation. In the light of the present observations, one role of this counter-current mechanism may be to alter the extent and activity of the vascular and lymphatic beds of the caudal oviduct to control regional temperature gradients in the lumen. Steroid modulation of the autonomic nervous regulation of smooth muscle layers in the oviduct may also be critical at this time (Brundin, 1969; Owman \& Sjoberg, 1976; Hunter, 1977). More specifically, oviduct tissues are known to have receptors for steroid hormones, prostaglandins and relaxin, and an involvement of these follicular hormones in triggering the phase of sperm activation and release is probable (Hunter, 1984). Prostaglandins, in particular, may act directly or via $\mathrm{Ca}^{2+}$ fluxes to promote enhanced motility (Kelly, 1981; Aitken \& Kelly, 1985), and ovarian follicular prostaglandins of the E, F and I series increase more than 100-, 10- and 5-fold, respectively, in pigs just before ovulation (Hunter \& Poyser, 1985). Hence, a local transfer of high concentrations of prostaglandins from preovulatory follicles to the oviducts might stimulate spermatozoa as well as contractile changes in the oviduct tissues, together ensuring that meeting of male and female gametes at the site of fertilization is closely co-ordinated.

A final comment concerns the site of the functional sperm reservoir in primates, and especially in humans. If this site is similarly the caudal region of the oviduct isthmus, and there is circumstantial evidence that this may be so (see Mortimer, 1985a, b), then the question arises as to whether a comparable preovulatory reduction in temperature is found in this region of the tract. Because the caudal isthmus is the intra-mural portion of the duct enveloped by uterine tissue in primates (Lisa, Gioia \& Rubin, 1954; Nilsson \& Reinius, 1969), temperature and gas tensions seem less likely to be modified locally by specific alterations of the vascular bed. Regulation of the pre- and periovulatory activity of spermatozoa may depend more on the nature of the oviduct secretions, particularly with respect to proteins such as immobilin (Usselman \& Cone, 1983). In the light of the prolonged lifespan of human spermatozoa in the female genital tract, on occasions extending to 3-4 days (Ahlgren, 1975; Edwards, 1980), and bearing in mind histological differences already demonstrated within the oviduct (Nilsson \& Reinius, 1969; Patek, 1974), further research might fruitfully examine preovulatory microenvironments in the human oviduct.

This study was supported by a grant from the Agricultural and Food Research Council. We thank Dr K. P. Bland, Dr R. G. Gosden, Dr W. J. Guild and Dr I. Wilmut for valuable comments on a draft of the manuscript; Mr T. Mackenzie, Department of Physiology, for loan of the thermistor probes and for technical assistance; and Mrs P. Gallie for typing the manuscript.

\section{References}

Ahlgren, M. (1975) Sperm transport to and survival in the human Fallopian tube. Gynecol. Invest. 6, 206-214.

Aitken, R.J. \& Kelly, R.W. (1985) Analysis of the direct effects of prostaglandins on human sperm function. J. Reprod. Fert. 73, 139-146.

Andersen, D.H. (1928) Comparative anatomy of the tubo-uterine junction. Histology and physiology in the sow. Am. J. Anat. 42, 255-305.

Borland, R.M., Hazra, S., Biggers, J.D. \& Lechene, C.P. (1977) The elemental composition of the environment of the gametes and preimplantation embryo during the initiation of pregnancy. Biol. Reprod. 16, 147-157. 
Brundin, J. (1969) Pharmacology of the oviduct. In The Mammalian Oviduct, pp. 251-269. Eds E. S. E. Hafez \& R. J. Blandau. University of Chicago Press, Chicago.

Burkman, L.J., Overstreet, J.W. \& Katz, D.F. (1984) A possible role for potassium and pyruvate in the modulation of sperm motility in the rabbit oviduct isthmus. J. Reprod. Fert. 71, 367-376.

Carr, D.W. \& Acott, E.S. (1984) Inhibition of bovine spermatozoa by cauda epididymal fluid. 1. Studies of a sperm motility quiescence factor. Biol. Reprod. $\mathbf{3 0}$, 913-925.

David, A., Vilensky, A. \& Nathan, H. (1972) Temperature changes in the different parts of the rabbit's oviduct. Int. J. Gynaec. Obstet. 10, 52-56.

Dziuk, P.J. (1973) Occurrence, control and induction of ovulation in pigs, sheep and cows. In Handbook of Physiology, Section 7, Endocrinology II, Part 1, pp. 143-152. Eds R. O. Greep \& E. B. Astwood. American Physiological Society, Washington, D.C.

Dziuk, P.J., Polge, C. \& Rowson, L.E.A. (1964) Intrauterine migration and mixing of embryos in swine following egg transfer. J. Anim. Sci. 23, 37-42.

Edwards, R.G. (1980) Conception in the Human Female, p. 559. Academic Press, London.

Einarsson, S. \& Viring, S. (1973) Effect of boar seminal plasma on the porcine uterus and the isthmus part of the oviducts in vitro. Acta vet. Scand. 14, 639-641.

Einarsson, S., Jones, B., Larsson, K. \& Viring, S. (1980) Distribution of small- and medium-sized molecules within the genital tract of artificially inseminated gilts. J. Reprod. Fert. 59, 453-457.

Fléchon, J.E. \& Hunter, R.H.F. (1981) Regulation of sperm transport by the utero-tubal junction and isthmus in pigs: a scanning electron microscope study. Tissue and Cell 13, 127-139.

Foxcroft, G.R. \& Van de Wiel, D.F.M. (1982) Endocrine control of the oestrous cycle. In Control of Pig Reproduction, pp. 161-177. Eds D. J. A. Cole \& G. R. Foxcroft. Butterworth Scientific, London.

Hunter, R.H.F. (1967) Porcine ovulation after injection of human chorionic gonadotrophin. Vet. Rec. 81, 21-23.

Hunter, R.H.F. (1977) Function and malfunction of the Fallopian tubes in relation to gametes, embryos and hormones. Eur. J. Obstet. Gynec. Reprod. Biol. 7, $267-283$.

Hunter, R.H.F. (1984) Pre-ovulatory arrest and periovulatory redistribution of competent spermatozoa in the isthmus of the pig oviduct. J. Reprod. Fert. 72, 203-211.

Hunter, R.H.F. \& Nichol, R. (1983) Transport of spermatozoa in the sheep oviduct: pre-ovulatory sequestering of cells in the caudal isthmus. $J$. exp. Zool. 228, 121-128.

Hunter, R.H.F. \& Nichol, R. (1986) Post-ovulatory progression of viable spermatozoa in the sheep oviduct, and the influence of multiple mating on their preovulatory distribution. Br. vet J. 142, 52-58.

Hunter, R.H.F. \& Poyser, N.L. (1985) Ovarian follicular fluid concentrations of prostaglandins $E_{2}, F_{2 \alpha}$ and $I_{2}$ during the pre-ovulatory period in pigs. Reprod. Nutr. Dévelop. 25, 909-918.

Hunter, R.H.F. \& Wilmut, I. (1984) Sperm transport in the cow: peri-ovulatory redistribution of viable cells within the oviduct. Reprod. Nutr. Dévelop. 24, $597-608$.

Hunter, R.H.F., Cook, B. \& Poyser, N.L. (1983) Regulation of oviduct function in pigs by local transfer of ovarian steroids and prostaglandins: a mechanism to influence sperm transport. Eur. J. Obstet. Gynec. Reprod. Biol. 14, 225-232.

Kelly, R.W. (1981) Prostaglandin synthesis in the male and female tract. J. Reprod. Fert. 62, 293-304.

Krzymowski, T., Kotwica, J. \& Stefanczyk, S. (1981) Venous-arterial counter-current transfer of $\left[{ }^{3} \mathrm{H}\right]$ testosterone in the vascular pedicle of the sow ovary. $J$. Reprod. Fert. 61, 317-323.

Liptrap, R.M. \& Raeside, J.I. (1966) Luteinizing hormone activity in blood and urinary oestrogen excretion by the sow at oestrus and ovulation. $J$. Reprod. Fert. 11, 439-446.

Lisa, J.R., Gioia, J.D. \& Rubin, I.C. (1954) Observations on the interstitial portion of the Fallopian tube. Surg. Gynec. Obstet. 99, 159-169.

Lovell, J.E. \& Getty, R. (1968) Fate of semen in the uterus of the sow: histologic study of endometrium during the 27 hours after natural service. Am. J. vet. Res. 29, 609-625.

Mortimer, D. (1985a) From the semen to the oocyte: the long route in vivo and in vitro short cut. In Human in vitro Fertilisation, pp. 93-107. Eds J. Testart \& R. Frydman. Colloq. INSERM. No. 24. Elsevier Biomedical Press, Amsterdam.

Mortimer, D. (1985b) The male factor in infertility. Part II. Sperm function testing. Current Problems in Obstet. Gynec. Fertil. 8, 1-75.

Nilsson, O. \& Reinius, S. (1969) Light and electron microscopic structure of the oviduct. In The Mammalian Oviduct, pp. 57-83. Eds E. S. E. Hafez \& R. J. Blandau. University of Chicago Press, Chicago.

Niswender, G.D., Reichert, L.E. \& Zimmerman, D.R. (1970) Radioimmunoassay of serum levels of luteinizing hormone throughout the estrous cycle in pigs. Endocrinology 87, 576-580.

Owman, Ch. \& Sjoberg, N.O. (1976) Influence of pregnancy and sex hormones on the system of short adrenergic neurons in the female reproductive tract. Proc. 5th Int. Congr. Endocr., Hamburg 1, 205-209.

Patek, E. (1974) The epithelium of the human Fallopian tube. Acta obstet. gynaec. scand. 53, Suppl. 31, 1-28.

Polge, C. (1978) Fertilization in the pig and horse. $J$. Reprod. Fert. 54, 461-470.

Usselman, M.C. \& Cone, R.A. (1983) Rat sperm are mechanically immobilized in the cauda epididymidis by 'immobilin', a high molecular weight glycoprotein. Biol. Reprod. 29, 1241-1253.

Wilmut, I. \& Hunter, R.H.F. (1984) Sperm transport into the oviducts of heifers mated early in oestrus. Reprod. Nutr. Dévelop. 24, 461-468.

Received 20 November 1985 